\section{P140 DOES THE LENGTH OF SYMPTOMS OF LONG COVID AFFECT PERCEIVED DYSPNOEA?}

A Barnes, G Heppenstall-Harris, S Kimyongur, E Bruchez, A Flatt, M Stolbrink, N Nwosu, L Watkins, G Tack. Liverpool University Hospitals Foundation Trust, Liverpool, UK

10.1136/thorax-2021-BTSabstracts.249

Introduction and Objective Long COVID or ongoing symptoms post-acute COVID infection can affect up to $20 \%$ of patients. ${ }^{1}$ Dyspnoea can be a cardinal symptom and have a significant impact on patients' quality of life and ability to function in society. NHS England devised a five-point plan for long COVID which included dedicated post COVID assessment clinics. $^{2}$

We aimed to review whether duration of symptoms influenced the severity of perceived dyspnoea (using Borg score) and breathlessness (using MRC dyspnoea score).

Methods Retrospective analysis of patients assessed in the Cheshire and Merseyside long COVID assessment hub between 1 February and 30 April 2021. Data was split into three categories based on duration of symptoms: 3-6 months, 6-12 months and over 12 months. The data was analysed using an ANOVA and tukey's multiple comparison test.

Results 332 patients were assessed, 7 were excluded from analysis.

Of the 325 :

- $251(75.7 \%)$ were female

- Age range 17-82 years, mean 47years

- $31(9.5 \%)$ patients received hospital treatment during initial illness

- 305 (94\%) patients reported exertional dyspnoea

Abstract P140 Table 1 Results comparing mean Borg/MRC scores against length of time post covid infection

\begin{tabular}{lll}
\hline $\begin{array}{l}\text { Time assessed in clinic from acute } \\
\text { infection (months) }\end{array}$ & $\begin{array}{l}\text { Mean Borg scale } \\
( \pm \text { SD })\end{array}$ & $\begin{array}{l}\text { Mean MRC score } \\
( \pm \text { SD })\end{array}$ \\
\hline $3-6$ & $5.2(2.0)$ & $2.6(0.8)$ \\
$6-12$ & $4.7(1.9)$ & $2.5(0.9)$ \\
$>12$ & $3.3(2.2)$ & $2.2(0.9)$ \\
\hline
\end{tabular}

Conclusion A significant difference was seen between Borg score in $3-6$ months and $>12(\mathrm{P}<0.01)$, suggesting that perceived dyspnoea due to long COVID improves with time. No significant difference was found in MRC dyspnoea score between each group. The reason for this remains unclear though improvement in perceived dyspnoea with time may offer reassurance to many long Covid patients. Further research is needed to determine if pulmonary rehabilitation provides a greater reduction in perceived dyspnoea.

\section{REFERENCES}

1. Ons.gov.uk. 2021. The prevalence of long COVID symptoms and COVID-19 complications - Office for National Statistics. [online] Available at: <https://www.ons.gov.uk/ news/statementsandletters/theprevalenceoflongcovidsymptomsandcovid19complications> [Accessed 22 June 2021]

2. England N, 2021. NHS England "NHS to offer 'long covid' sufferers help at specialist centres. [online] England.nhs.uk. Available at: <https://www.england.nhs. uk/2020/10/nhs-to-offer-long-covid-help/> [Accessed 24 June 2021].

\section{P141 OBSERVATIONAL COHORT STUDY OF PATIENTS REFERRED BY THEIR GP TO A COVID RESPIRATORY CLINIC}

H May, R Chamoto, S McConnell, R Stacey, R Horne, A Jefferson, F Leahy, J Holme. Wythenshawe Hospital, Manchester, UK

\subsection{6/thorax-2021-BTSabstracts. 250}

Introduction and Objectives The COVID-19 pandemic resulted in many patients suffering chronic post viral symptoms being referred by their GP to our respiratory Covid clinic. This study describes the demographics, symptoms, radiology, and lung function results for these patients to date. This will provide evidence-based data to improve services and promote recovery.

Method Patients completed the C19 Yorkshire COVID Rehab screening tool and we designed a proforma for clinical assessment. Investigations were performed using a clinical pathway we designed in accordance with national guidelines, and standards of care (NHS England, 2021). Symptoms scores, investigation results, management plans and rates of referral to other specialties were collated.

Results Sixty-six (71\%) patients were female and seventy-five (80\%) were of white British ethnicity, with a mean age of fifty-one years. The most frequent pre-existing health complaint was anxiety and depression (27\%) followed by asthma (17\%). $83 \%$ suffered greater levels of fatigue post COVID and $80 \%$ reported increasing exertional breathlessness. $73 \%$ recorded difficulties with concentration and short-term memory. $80 \%$ reported problems carrying out usual daily activities. Fifteen (17.5\%) had an abnormal chest x-ray (7 resolving COVID, 5 cardiomegaly with normal lungs, 1 pleural plaques, 1 COPD 1 unknown). Sixty-six lung function tests were requested with twenty-six of the thirty-one (84\%) performed to date being normal. Four had mild airflow obstruction (including one with COPD).

Conclusion Overall, we concluded that most patients had normal chest radiographs and lung function tests. Long Covid causes a heavy symptom burden significantly affecting the individual's quality of life with chronic breathlessness and fatigue being the most common symptoms. Females, of white British origin with a mean age of fifty-one were most frequently referred to our clinic.

The results prompted us to build a suitable management plan for these patients and we questioned why predominantly white British women were referred, as data has indicated Covid 19 disproportionately affected ethnic minority groups. (Razai et al, 2021)

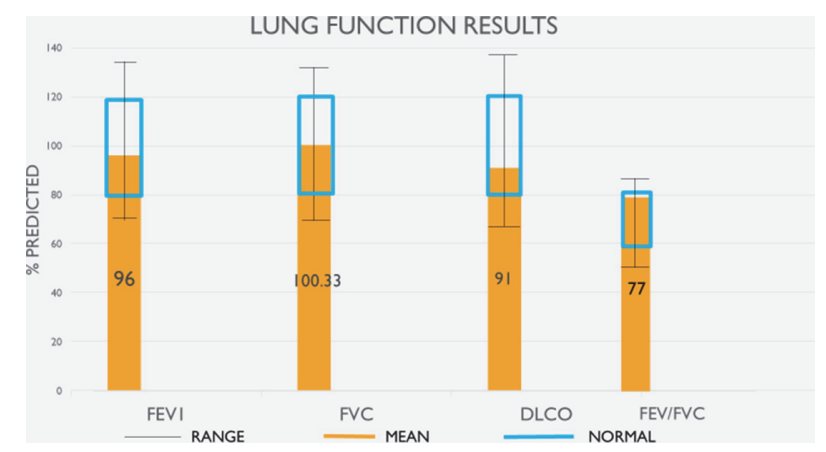

Abstract P141 Figure 1 Lung function results 


\section{REFERENCES}

1. NHS England 2021, National Guidance for post COVID syndrome assessment clinics, viewed 21/6/20201, available at < https://www.england.nhs.uk/coronavirus/ wp-content/uploads/sites/52/2020/11/C1248-national-guidance-post-covid-syndrome-assessment-clinics-v2.pdf>

2. Razai MS, Kankam HKN, Majeed A, Esmail A, Williams DR. Mitigating ethnic disparities in covid 19 and beyond. The Bmj 2021;372:m4921.

\section{P142 CHAOTIC BREATHING IN POST COVID-19 BREATHLESSNESS: A KEY FEATURE CHARACTERISED BY APPROXIMATE ENTROPY}

${ }^{1} \mathrm{CB}$ Samaranayake, ${ }^{1} \mathrm{C}$ Warren, ${ }^{1} \mathrm{~S}$ Rhamie, ${ }^{1} \mathrm{LC}$ Price, ${ }^{1} \mathrm{C} \mathrm{McCabe},{ }^{2} \mathrm{G}$ Haji, ${ }^{1} \mathrm{JH}$ Hull. ${ }^{1}$ Royal Brompton Hospital, Guy's and St Thomas' NHS Trust, London, UK; ${ }^{2}$ Hammersmith Hospital, Imperial College Health Care NHS Trust, London, UK

\subsection{6/thorax-2021-BTSabstracts.251}

Abstract P142 Table 1 Baseline characteristics and exercise measurements

\begin{tabular}{|c|c|c|c|}
\hline & $\begin{array}{l}\text { Post COVID-19 } \\
\text { BPD } \\
(\mathrm{N}=20)\end{array}$ & $\begin{array}{l}\text { Non-COVID } \\
\text { BPD } \\
(\mathrm{N}=20)\end{array}$ & $\begin{array}{l}\text { Healthy } \\
\text { controls } \\
(\mathrm{N}=15)\end{array}$ \\
\hline \multicolumn{4}{|l|}{ BASELINE CHARACTERISTICS } \\
\hline Age/years & $41(10)$ & 49 (14) & $50(18)$ \\
\hline Gender M:F & 6:14 & 6:14 & 9:6 \\
\hline BMI $\left(\mathrm{kg} / \mathrm{m}^{2}\right)$ & $25(4)$ & $26(5)$ & $25(4)$ \\
\hline Nijmegen score (/64) & $23(12-44)$ & $23(14-41)$ & - \\
\hline FEV1 (\% pred) & $111(13)$ & $107(16)$ & $96(6)$ \\
\hline FVC (\% pred) & 118 (14) & $114(16)$ & $107(12)$ \\
\hline FEV1/FVC Ratio & $80(6)$ & 78 (6) & $75(12)$ \\
\hline Resting Sp02 (\%) & $98(95-100)$ & $99(94-100)$ & $97(96-99)$ \\
\hline $\begin{array}{l}\text { Resting HCO3 - (earlobe) (mmol/ } \\
\text { L) }\end{array}$ & $24(5)$ & $22(3)$ & $24(2)$ \\
\hline Resting PaC02 (kPa) & $4.4(0.8)$ & $4.3(0.7)$ & $4.7(0.5)$ \\
\hline $\begin{array}{l}\text { Resting BORG CR-10 dyspnoea (/ } \\
\text { 10) }\end{array}$ & $0.7(0.8)$ & $1.4(1.3)$ & $0.2(0.6)$ \\
\hline \multicolumn{4}{|l|}{ PEAK exercise CPET Variables } \\
\hline Duration of test (minutes) & $10(4)$ & $9(2)$ & $15(3)$ \\
\hline Main reason cited for exercise & Legs $=6$ & Legs $=8$ & Legs $=6$ \\
\hline cessation & Breathing $=14$ & Breathing $=12$ & Breathing $=4$ \\
\hline BORG CR-10 dyspnoea (/10) & End=5.3 (2.3) & End=4.2 (1.5) & End=4.1 $(1.7)$ \\
\hline Peak V02 (L/min) & $2.18(0.87)$ & $1.52(0.62)$ & $2.77(1.22)$ \\
\hline Peak V02 (\% predicted) & $106.5(33.1)$ & $79.8(17.5)$ & $124.8(27.3)$ \\
\hline Peak V02 (mL/min/kg) & $29.6(7.6)$ & $20.7(7.1)$ & $37.8(14.8)$ \\
\hline Peak Heart Rate (beats/min) & $170(12.6)$ & $141(26)$ & $167(15)$ \\
\hline Heart Rate Reserve (beats/min) & $20(19)$ & $30(20)$ & $2(13)$ \\
\hline Peak VE (L/min) & $89(26)$ & $60(27)$ & $96(35)$ \\
\hline Peak Tidal Volume (L) & $2.6(1.3)$ & $1.86(0.88)$ & $2.37(0.71)$ \\
\hline Peak Breathing Frequency (/min) & $43(23)$ & $31(9)$ & $33(8)$ \\
\hline Peak Sp02 (\%) & $97(93-100)$ & $99(94-100)$ & $95(73-98)$ \\
\hline \multicolumn{4}{|l|}{ PEAK exercise gas exchange values } \\
\hline $\mathrm{PaO2}(\mathrm{kPa})$ & $13.3(3.2)$ & $13.8(1.2)$ & $13.7(1.2)$ \\
\hline $\mathrm{PaC02}(\mathrm{kPa})$ & $4.4(1.1)$ & $4.2(0.7)$ & $4.1(0.7)$ \\
\hline PETCO2 (kPa) & $4.4(0.6)$ & $4.3(0.5)$ & $4.8(0.8)$ \\
\hline $\mathrm{P}(\mathrm{A}-\mathrm{a}) 02$ difference $(\mathrm{kPa})$ & $2.8(1.2)$ & $2.1(0.9)$ & $2.6(0.9)$ \\
\hline $\mathrm{P}(\mathrm{a}-\mathrm{ET}) \mathrm{CO2}$ difference $(\mathrm{kPa})$ & $-0.10(0.25)$ & $-0.09(0.37)$ & $-0.35(0.53)$ \\
\hline \multicolumn{4}{|c|}{ Approximate entropy (ApEn) of ventilatory variables during incremental exercise } \\
\hline ApEn Tidal Volume & $1.61(0.05)$ & $1.28(0.23)$ & $1.02(0.29)$ \\
\hline ApEn Breathing Frequency & $1.40(0.10)$ & $1.41(0.20)$ & $1.32(0.21)$ \\
\hline ApEn Minute Ventilation & $1.22(0.11)$ & $0.97(0.30)$ & $0.65(0.23)$ \\
\hline
\end{tabular}

Data shown as mean (SD) or median (range); M:F: Male:Female; BMI: body mass index; FEV1: forced expiratory volume in the first second; FVC: forced vital capacity; Sp02; oxygen saturation; CPET: cardiopulmonary exercise test; VO2: oxygen consumption; VE:
Background Exertional dyspnoea is a pervasive clinical feature for many patients following COVID-19 infection, with a high prevalence of breathing pattern disorder (BPD) reported. In this study we aimed to characterise exercise ventilatory patterns in patients with exertional dyspnoea following COVID-19 infection, using a non-linear statistical approach.

Method Patients who underwent cardiopulmonary exercise testing (CPET) for unexplained exertional breathlessness following COVID-19 infection, confirmed on PCR or antibody testing, were audited, between May 20 and May 21. Those with evidence of persistent parenchymal changes, thromboembolic disease, or cardiac dysfunction were excluded. Ventilatory irregularity during exercise quantified by approximate entropy (ApEn) was assessed and compared to a historical cohort of controls with non-COVID19 related BPD and health individuals.

Results Over the study period, 20 patients (mean age 41 years (SD 10), 14 (70\%) female) fulfilled inclusion criteria and underwent CPET at a median of 4 months (range 3-10) following infection. Chest and cardiac imaging was normal in all patients who had follow-up investigations. Spirometric indices were also normal and the mean (SD) DLCO and KCO were 83\% (11.7) and 94\% (9.5) predicted, respectively. On exercise testing, most COVID-19 patients stopped secondary to dyspnoea, with a BORG median at 5 (i.e. 'severe') but had a normal $\mathrm{VO}_{2}$ peak $(107 \%$ predicted) and gas exchange response, with low indices of VQ mismatching (table 1). ApEN was elevated for tidal volume and VE but similar to non-COVID BPD.

Conclusions Post COVID BPD can be characterised by application of non-linear statistical modelling of exercise ventilatory data. This approach now needs further validation to facilitate application in automated CPET equipment, to identify and highlight this important differential diagnosis.

\section{P143 'IT GIVES YOU THAT HOPE, KNOWING THAT YOU ARE NOT ALONE' - THE JOURNEY OF COVID-19 RECOVERY AND THE REHABILITATION BOAT}

${ }^{1} \mathrm{C}$ Gerlis, ${ }^{1} \mathrm{AC}$ Barradell, ${ }^{1} \mathrm{NY}$ Gardiner, ${ }^{1} \mathrm{EJ}$ Chaplin, ${ }^{1} \mathrm{ACN}$ Watt, ${ }^{2} \mathrm{SJ}$ Singh, ${ }^{1} \mathrm{E}$ Daynes. ${ }^{1}$ Centre for Exercise and Rehabilitation Science, Leicester NIHR Biomedical Research Centre - Respiratory, Glenfield Hospital, Leicester, UK; ${ }^{2}$ Department of Respiratory Sciences, University of Leicester, Leicester, UK

\subsection{6/thorax-2021-BTSabstracts.252}

Introduction The persistent symptoms of COVID-19 are well documented. ${ }^{1}$ There is encouraging early data for improvements in fatigue, exercise capacity and cognition in those attending a supervised rehabilitation programme. ${ }^{2}$ There is no published data on its perceived acceptability. This study aims to understand patients' lived experience of recovery from this novel disease including experiences of attending a COVID-19 rehabilitation programme.

Methods Patients who attended COVID-19 rehabilitation were invited to take part in virtual focus groups or 1:1 interviews conducted by independent researchers. Inductive thematic analysis was used. A reflective log provided a transparent account of data collection and analysis. Transcripts were coded by the first author and one other researcher, themes were generated and agreed. 